\title{
Clinical utility of valsartan in treatment of children and adolescents with high blood pressure
}

This article was published in the following Dove Press journal:

Adolescent Health, Medicine and Therapeutics

16 September 2011

Number of times this article has been viewed

\author{
Manu Kaushik' \\ Syed M Mohiuddin ${ }^{2}$ \\ 'Division of Cardiology, ${ }^{2}$ Department \\ of Internal Medicine, Creighton \\ University Medical Center, Omaha, \\ NE, USA
}

\begin{abstract}
The incidence of hypertension in the pediatric population has been increasing secondary to lifestyle changes in children and adolescents. Recent studies have enhanced our understanding of the treatment of pediatric hypertension. Angiotensin-converting enzyme inhibitors have traditionally been the most commonly used class of medication in children with hypertension. This is partly due to the important role of the renin angiotensin aldosterone system pathway in the mediation of pediatric hypertension. Angiotensin receptor blockers provide a reasonable alternative to angiotensin-converting enzyme inhibitors. The need for better tolerated antihypertensives had led to development of many new antihypertensives. Valsartan is a relatively novel angiotensin receptor blocker that has been shown to be effective in the treatment of pediatric hypertension. Two recent trials have demonstrated the efficacy of valsartan monotherapy in the pediatric population aged 1-16 years. Once-daily oral preparations of valsartan achieve adequate blood pressure control in the pediatric population. Lack of generic formulations is an important disadvantage. Plasma levels are predictable and clearance is primarily by the liver. Valsartan should be prescribed cautiously for sexually active adolescent females due to concern about angiotensin receptor blocker fetopathy. Otherwise, the drug has infrequent side effects. In summary, valsartan is a new and useful alternative to conventional antihypertensive therapy in pediatric population.
\end{abstract}

Keywords: valsartan, angiotensin receptor blockers, pediatrics, children, adolescents, hypertension, safety, efficacy

\section{Introduction}

Drug therapy in children has traditionally been based on expert opinion, unlike drug therapy in adults. There is a relative lack of data on efficacy as well as safety for most drugs in children due to lack of initiative in enrollment of pediatric populations in many drug trials. Most treatment recommendations in children are extrapolations of data from adult populations. However, following the Food and Drug Administration Modernization Act of 1997, there has been an exponential increase in data on the safety and efficacy of drug use for pediatric diseases. ${ }^{1}$ Indeed, these changes have enhanced our understanding of treatment of hypertension in the pediatric population. Many antihypertensive agents have been studied in pediatric populations in recent years and Valsartan is one of these. Valsartan is an angiotensin receptor blocker that was initially approved for treatment of hypertension in adults. It subsequently found uses in several other areas of pharmacotherapeutics in both adult and pediatric populations. ${ }^{2}$ It is a relatively novel orally formulated angiotensin receptor blocker that has been approved by the Food and Drug Administration (FDA) for use in the pediatric population over the age of six years. It has also been used in Europe for treating pediatric hypertension.
Correspondence: Syed M Mohiuddin 60 I N 30th Street, Suite 5850,

NE 68131, USA

$\mathrm{Tel}+\mathrm{I} 4022804570$

Fax +I 402280561 I

Emailsmm@creighton.edu 
Herein, we attempt to review the current role of valsartan in pediatric diseases, with special attention to pediatric hypertension.

\section{Hypertension in children}

Guidelines recommend the recording of blood pressure in all otherwise healthy children over the age of three years during routine health visits. ${ }^{3}$ An average of three blood pressure readings should be used to diagnose hypertension. The diagnosis of hypertension in children is made based on detection of systolic or diastolic blood pressure $\geq$ the 95th percentile for gender, age, and height plus $5 \mathrm{mmHg} .{ }^{4}$ Systolic or diastolic blood pressure $\geq$ the 90th percentile or a blood pressure reading more than $120 / 80 \mathrm{mmHg}$ is deemed as prehypertension. These percentiles are based on data from population-based studies and incorporate the results from the National Health And Nutrition Examination Survey (NHANES) data from 1999-2000 in the US. It is uncertain if the effects of racial differences in blood pressure affect the diagnosis of hypertension in the pediatric population. Interestingly, blood pressure in the more recent NHANES 1999-2000 survey was higher than average blood pressures in similar age groups in 1988-1994. ${ }^{5}$ This reflects the increasing incidence of obesity and metabolic syndrome in childhood and adolescence in developed countries. ${ }^{6}$ Recent estimates report the incidence of hypertension in US children to be $3.2 \%$, highlighting the magnitude of the problem. ${ }^{7}$ Furthermore, the presence of elevated blood pressure in childhood and adolescence may predict development of hypertension in adulthood. ${ }^{8}$

Treatment of primary hypertension in children and adolescents without symptoms or target organ damage is directed towards lifestyle modification and weight loss. ${ }^{4}$ Pharmacotherapy is indicated for treatment of symptomatic hypertension, secondary hypertension, or hypertension with target organ damage in children. In addition, diabetic children with HTN, and those who do not respond to nonpharmacological measures should be treated with pharmacotherapy. ${ }^{4}$ Data on the efficacy and safety of these antihypertensives is rather limited in the pediatric population compared with the adult population. Hence, the guidelines do not support the use of one particular class of antihypertensives or agent over others, and leave the decision to the preference of the treating physician. ${ }^{4}$ However, patients with certain clinical conditions, such as diabetes, may warrant consideration of special classes of antihypertensives, such as angiotensin receptor blockers and angiotensin-converting enzyme inhibitors for the treatment of hypertension. Certain forms of pediatric hypertension are dependent on the renin angiotensin aldosterone system (RAAS) pathway and may be best treated with drugs acting on this pathway. Finally, the choice of antihypertensives is often directed by the adverse effect profile of a particular class of medication. Currently, angiotensin-converting enzyme inhibitors and angiotensin receptor blockers appear to be the most commonly used classes of antihypertensives in adults due primarily to the relatively infrequent side effects of these agents. ${ }^{9}$

\section{Current trends in use of antihypertensives in pediatric populations}

Currently, multiple antihypertensive agents are approved for use in children (Table 1) ${ }^{10} \mathrm{~A}$ significant number of these medications have been approved since the passing of the Food and Drug Administration Modernization Act in the US in 1997 and other legislative changes and initiatives. ${ }^{10}$ Nevertheless, market trends suggest disproportionately more use of certain agents in the pediatric population. Even amongst the commonly used classes of drugs, angiotensin receptor blockers and angiotensin-converting enzyme inhibitors are more commonly prescribed classes compared with diuretics or beta-blockers in the pediatric population. ${ }^{11}$ Angiotensin receptor blockers as monotherapy or as fixeddose combinations contributed to $26.3 \%$ of pediatric hypertension prescriptions in Europe ${ }^{11}$ (Figure 1). This trend indicates a significant physician and pediatrician preference for these agents independent of compelling indications. A low

Table I Pediatric labeling of antihypertensive medications: effect of the FDAMA and successor legislation

\begin{tabular}{|c|c|c|}
\hline $\begin{array}{l}\text { Pediatric labeling } \\
\text { before FDAMA }\end{array}$ & $\begin{array}{l}\text { Pediatric labeling } \\
\text { since FDAMA }\end{array}$ & $\begin{array}{l}\text { Under study, awaiting } \\
\text { labeling, or anticipated } \\
\text { future study }\end{array}$ \\
\hline Captopril & Amlodipine & Aliskiren \\
\hline Chlorothiazide & Benazepril & Candesartan \\
\hline Diazoxide & Enalapril & Olmesartan \\
\hline Furosemide & Eplerenone & Ramipril \\
\hline Hydralazine & Fenoldopam & Sodium nitroprusside \\
\hline Hydrochlorothiazide & Fosinopril & Telmisartan \\
\hline Methyldopa & Irbesartan & \\
\hline Minoxidil & Losartan & \\
\hline Propranolol & Lisinopril & \\
\hline \multirow[t]{2}{*}{ Spironolactone } & Metoprolol & \\
\hline & Valsartan & \\
\hline
\end{tabular}

Note: Copyright $\odot 2010$. Reprinted from Kavey RE, Daniels SR, Flynn JT. Management of high blood pressure in children and adolescents. Cardiol Clin. 2010;28:597-607, with permission from Elsevier. ${ }^{10}$

Abbreviation: FDAMA, Food and Drug Administration Modernization Act 1997. 


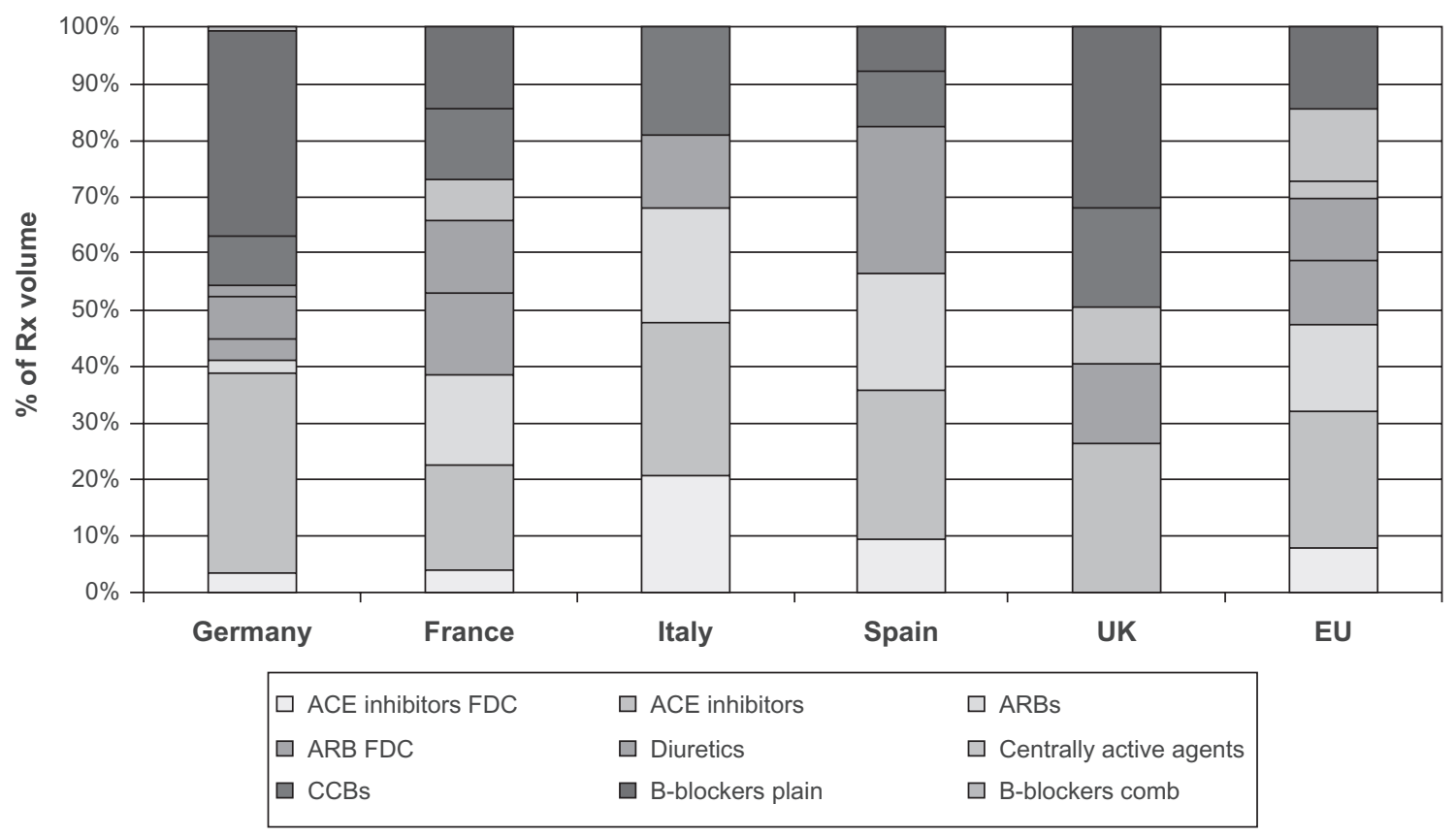

Figure I Use of common antihypertensives in major European countries.

Note: Reprinted by permission from Macmillan Publishers Ltd: Journal of Human Hypertension. Balkrishnan R, Phatak H, Gleim G, Karve S. Assessment of the use of angiotensin receptor blockers in major European markets among paediatric population for treating essential hypertension. J Hum Hypertens. 2009;23:420-425. Copyright @ 2009."

Abbreviations: ACE, angiotensin-converting enzyme; ARB, angiotensin receptor blocker; FDC, fixed-dose combination; CCBs, calcium channel blockers; Comb, combination; EU, European Union.

incidence of side effects with these medications may partly explain this preference.

\section{Pathophysiology of pediatric hypertension and role of RAAS system}

Changes in the RAAS system play a crucial role in the pathophysiology of pediatric hypertension. Renin released from the juxtaglomerular apparatus leads to conversion of angiotensinogen, a decapeptide, to a truncated form, ie, angiotensin I. Angiotensin I is then converted to angiotensin II by the angiotensin-converting enzyme. Angiotensin II binds to angiotensin II receptors to mediate its hypertensive effects. Mechanisms of the hypertensive effects include arteriolar constriction, sympathetic autonomic system activation, aldosterone-mediated sodium and water retention, and antidiuretic hormone-mediated water retention. Most of these antihypertensive effects are mediated through angiotensin II receptor type $1\left(\mathrm{AT}_{1}\right)$. Angiotensinconverting enzyme inhibitors and angiotensin receptor blockers are two major classes of medication that act on the RAAS by causing angiotensin-converting enzyme inhibition and angiotensin receptor blockade, respectively. Angiotensin receptor blockers may differ in their degree of selectivity in binding to $\mathrm{AT}_{1}$ receptors compared with angiotensin II type $2\left(\mathrm{AT}_{2}\right)$ receptors. $\mathrm{AT}_{2}$ receptors promote vasodilatation, apoptosis, and cell proliferation, and inhibit cell growth and hypertrophy. $\mathrm{AT}_{2}$ receptor blockade may theoretically negate some of the beneficial effects of $\mathrm{AT}_{1}$ receptor blockade.

RAAS activation might play an important role in obesityrelated fluid retention and hypertension, as evidenced by increased levels of renin activity, angiotensin II, and aldosterone in obesity. ${ }^{12}$ Common causes of secondary hypertension, such as renovascular hypertension and parenchymal renal disease, are mediated through the RAAS. ${ }^{9}$ Activation of the RAAS also mediates a vicious circle of renal disease and hypertension in both children and adults. In children, intensive blood pressure control and downregulation of the RAAS using angiotensin-converting enzyme inhibitors has been shown to delay progression of chronic kidney disease. ${ }^{13}$ Young adults and children at risk of hypertension appear to develop changes in renal hemodynamics. Renin and aldosterone levels correlate with the degree of risk of subsequent development of hypertension. ${ }^{14}$ This implies a major role of antihypertensive agents acting on these pathways in managing hypertension in children. Recent data support the possible use of plasma renin activity to identify patients with difficult to control hypertension and excessive RAAS activity. These patients may respond better to antihypertensives 
inhibiting the RAAS, such as angiotensin-converting enzyme inhibitors and angiotensin receptor blockers. ${ }^{15}$

\section{Current status of valsartan}

Valsartan is a nonpeptide angiotensin II receptor blocker approved by the FDA for treatment of hypertension in children. ${ }^{16}$ Valsartan was initially approved in Europe for treatment of hypertension in adults, but was subsequently approved in the US for adult prescription and finally, in 2007 , was approved for use in children aged 6-16 years. Valsartan has been evaluated either as monotherapy or as a fixed-dose combination with diuretics in more than 60 studies including at least 100,000 patients. ${ }^{17}$ Being an angiotensin receptor blocker, it confers the benefit of a lower incidence of cough and angioedema compared with angiotensin-converting enzyme inhibitors. ${ }^{17}$ Because of its action of RAAS inhibition, it is one of the antihypertensive agents of choice in patients with heart failure, diabetes mellitus, and/or chronic kidney disease.

\section{Pharmacokinetics}

Valsartan is a tetrazole derivative containing acid, giving it a pKa of 4.73 and making it a compound soluble in the neutral $\mathrm{pH}$ range. Thus, at physiological $\mathrm{pH}$, the drug exists mainly in the ionized form and is highly soluble. It is less soluble at gastric $\mathrm{pH}$, thus slowing the dissolution of oral valsartan preparations in the stomach. ${ }^{18}$ Studies in adults reveal that the oral bioavailability of valsartan is in the range of $23 \%-39 \%{ }^{18}$ The absorption process consists of an initial rapid absorption phase followed by a second slow absorption phase. ${ }^{18}$ In children, plasma levels peak at two hours after oral administration and subsequently reduce in a biexponential manner. ${ }^{19}$ The plasma half-life is about four hours in children under six years of age. ${ }^{19}$ In children aged 6-12 years, the plasma half-life is about five hours. ${ }^{19}$ In contrast with losartan, which requires oxidative transformation to the active compound, valsartan is minimally metabolized. ${ }^{20}$ Overall, less than $20 \%$ of the drug is metabolized (in the liver), thus having limited drug-drug interactions. ${ }^{17}$ About $7.3 \%-12.6 \%$ of the oral dose is excreted unchanged in the urine. ${ }^{18}$ Thus, most of the drug is excreted unchanged through bile in feces. No significant dosage adjustment is needed in mild to moderate kidney or liver disease. Clearance is not significantly affected by age after correcting for fat free body mass. ${ }^{19,21}$ The rate of clearance is $0.076-0.098 \mathrm{~L} /$ hour $/ \mathrm{kg}$ in children aged $1-16$ years. ${ }^{19}$ The liver is responsible for most of the plasma clearance, but the clearance is slow at $2 \mathrm{~L} /$ hour. ${ }^{18}$ The drug is minimally bound to adipose tissue in the body. ${ }^{18}$ Valsartan is more than
$90 \%$ protein-bound, which is likely to be responsible for its slow clearance from plasma.

\section{Antihypertensive efficacy}

Valsartan has been studied in a variety of clinical settings of hypertensive populations. It has been specifically evaluated in pediatric populations aged $1-5$ years and 6-16 years. ${ }^{22,23}$ In adults, valsartan has been compared with more traditional antihypertensives, such as beta-blockers, other angiotensin receptor blockers, calcium channel blockers, and angiotensin-converting enzyme inhibitors, and has been found to be similarly efficacious. ${ }^{17}$ Valsartan has been proven effective in treating hypertension as both monotherapy as well as in combination therapy in adults. ${ }^{17}$ It has been studied in adults in fixed-dose combination with hydrochlorothiazide, with amlodipine, and with aliskiren. ${ }^{17}$ The valsartan-hydrochlorothiazide combination has been shown to have a faster time to peak action compared with valsartan monotherapy. ${ }^{24}$ With valsartan monotherapy, the usual time to maximal antihypertensive effect is about two weeks. ${ }^{23}$ Although valsartan is available as a fixed-dose combination with hydrochlorothiazide and with amlodipine, the efficacy of fixed dose combinations has not been tested in children. However, because the targets to treat for hypertension are more ambiguous in children, use of fixed-dose combinations may not be unreasonable in certain clinical situations.

Valsartan as monotherapy has been shown to produce a consistent dose-dependent reduction in both systolic and diastolic blood pressures. ${ }^{23}$ In the study by Wells et al in children aged 6-16 years, there was an increasing benefit of higher doses of valsartan when separated into low, medium, and high doses ${ }^{23}$ (Figure 2). Dose separation was based on body weight, with children weighing less than $35 \mathrm{~kg}$ receiving $10 \mathrm{mg}, 40 \mathrm{mg}$, and $80 \mathrm{mg}$ of valsartan as a low, medium, and high dose, respectively. Children weighing over $35 \mathrm{~kg}$ received $20 \mathrm{mg}, 80 \mathrm{mg}$, and $160 \mathrm{mg}$ of valsartan as a low, medium and high dose, respectively. ${ }^{23}$ This represented a dose range of $0.4-2.7 \mathrm{mg} / \mathrm{kg}$. The benefit in reduction of blood pressure was observed irrespective of race (black or nonblack), age (6-11 years or 12-16 years), gender, or weight $(<35 \mathrm{~kg}$ or $\geq 35 \mathrm{~kg}$ ). ${ }^{23}$ An oral dose of $320 \mathrm{mg}$, which is the maximum recommended valsartan dose in adults, was not tried in this study. However, the blood pressure reduction was comparable with the blood pressure reduction achieved by losartan in children aged 6-16 years. ${ }^{23,26}$ In a similar study by Flynn et al, valsartan was found to reduce both systolic and diastolic blood pressure in low-dose, medium-dose, and high-dose groups in children aged $1-5$ years. ${ }^{22}$ The results were consistent across gender, weight, and race, regardless of prior other antihyper- 
Mean SSBP $\square \mathbb{Z}$ Mean SDBP

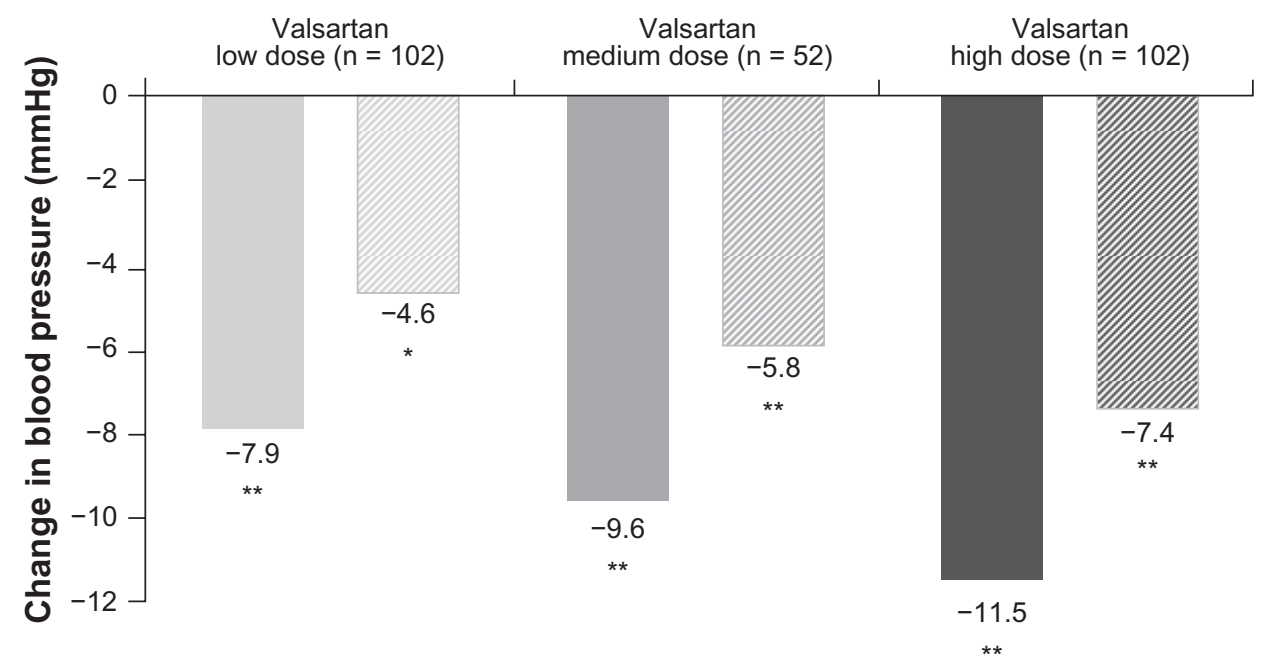

Figure 2 Dose-dependent reduction in mean sitting systolic blood pressure and diastolic blood pressure in children aged 6-16 years.

Note: Copyright (C 2009. John Wiley and Sons. Reproduced with permission from Habtemariam B, Sallas W, Sunkara G, Kern S, Jarugula V, Pillai G. Population pharmacokinetics of valsartan in pediatrics. Drug Metab Pharmacokinet. 2009;24:145-152. ${ }^{21}$

Abbreviations: SSBP, sitting systolic blood pressure; SDBP, sitting diastolic blood pressure.

tensive use. Interestingly, the antihypertensive response in this age group was not found to be dose-related, and was similar to that observed in adults. ${ }^{25}$ Effects of valsartan $80-160 \mathrm{mg}$ are comparable with those of losartan 50-100 mg. ${ }^{23}$

Other cardiovascular benefits, such as in heart failure, post-myocardial infarction states, and stroke protection in hypertensive adults, have not been tested in pediatric populations. Indeed, the close association of these conditions with atherosclerotic vascular disease makes them rather uncommon entities in the pediatric population. Angiotensin receptor blockers, when added to angiotensin-converting enzyme inhibitors in proteinuric children, provide incremental benefit in term of reducing proteinuria, independent of their blood pressure-lowering effect. ${ }^{27}$ Furthermore, they have been found to reduce left ventricular hypertrophy in a pediatric population with hypertension and renal disease. ${ }^{27}$

\section{Palatability and dosing}

Palatability is an important consideration while prescribing medications to children. Meier et al compared the palatability of various angiotensin receptor blocker tablets in children aged 4-11 years. ${ }^{28}$ Pulverized tablets of valsartan were reported to be inferior in taste when compared with similar preparations of candesartan and telmisartan. Valsartan can also be dispensed in a suspension form prepared from its tablets. ${ }^{22}$ There has been no comparison of valsartan suspension with other angiotensin receptor blocker suspensions regarding palatability.
The two landmark studies of valsartan in pediatric populations tested doses of $10-160 \mathrm{mg}^{22,23}$ These doses equated to doses of $0.1-4.6 \mathrm{mg} / \mathrm{kg}$ (mean doses $0.4-2.7 \mathrm{mg} / \mathrm{kg}$ ) in children aged 6-16 years. ${ }^{23} \mathrm{~A}$ valsartan dose $<0.4 \mathrm{mg} / \mathrm{kg}$ is unlikely to be significantly effective. ${ }^{22}$ The recommended dosage of valsartan for treating hypertension in the pediatric population is $1.3-2.7 \mathrm{mg} / \mathrm{kg}$, with a starting dose of $1.3 \mathrm{mg} / \mathrm{kg}$. ${ }^{16}$ This amounts to a starting dose of $40 \mathrm{mg}$ in children below $35 \mathrm{~kg}$ and $20 \mathrm{mg}$ for children below $15 \mathrm{~kg}$. Doses $>160 \mathrm{mg}$ $(4.7 \mathrm{mg} / \mathrm{kg})$ have not been tested in children and may not be recommended. Valsartan has a half-life of about seven hours, which is shorter than the half-life for other newer angiotensin receptor blockers, such as olmesartan and telmisartan. A clinically significant difference in duration of action is noted only when compared with telmisartan. Nevertheless, in adult studies, valsartan prescribed as a once-daily dose has been shown to provide a sustained effect in reducing diastolic as well as systolic blood pressure upon ambulatory blood pressure monitoring both during the daytime and during the night-time. ${ }^{29}$ Comparison of daytime and night-time dosing has shown no difference in sustainability or degree of blood pressure reduction. ${ }^{30}$ Thus, valsartan may be taken at any time of the day for treatment of hypertension. Data from heart failure trials in adults support twice-daily dosing.

\section{Adverse effects and tolerance}

Angiotensin receptor blockers are the preferred agents for hypertension in terms of side effect profile and tolerance, and 
are considered even better than angiotensin-converting enzyme inhibitors in this regard. Studies in pediatric populations have revealed that headache might be the most common side effect. In the study by Wells et al, headache was observed in more than $5 \%$ of patients, regardless of their blood pressure. ${ }^{23}$ Another common adverse effect is dose-related dizziness, and this may be caused by excessive hypotension. Another predictable class effect of the angiotensin receptor blockers is hyperkalemia. Serious hyperkalemia has been reported, ${ }^{23}$ and serum potassium levels should be monitored, especially in children with renal disease and in patients who are concomitantly taking angiotensin-converting enzyme inhibitors or potassium-sparing diuretics and angiotensin receptor blockers. Hyperkalemia is less common with a fixed-dose valsartan-hydrochlorothiazide combination compared with valsartan alone. ${ }^{22}$ Cough and angioedema are relatively rare compared with the angiotensinconverting enzyme inhibitors. In children aged 1-5 years, no significant difference was noted in the overall frequency of adverse effects between valsartan and placebo. ${ }^{22}$ Adverse effects observed in this study that were deemed possibly valsartan-related included pruritus and rash, hypertriglyceridemia, headache, hepatitis, hyperkalemia, worsening renal function, and thrombocytopenia. Discontinuation of drugs due to adverse effects was rare in both the above trials. ${ }^{22,23}$

The effects of valsartan on growth and development during infancy and early childhood have been evaluated by Flynn et al. ${ }^{22}$ Valsartan was found to have no effect on body mass index and height when corrected for age, and did not impact the expected increase in head circumference of children. Expected progress occurred in neurological development parameters such as fine motor skills, gross motor skills, and various parameters of language and social development. Adolescent females prescribed valsartan should be counseled regarding effective contraception, because there is a reasonable risk of fetal developmental defects during pregnancy. In children with clinical suspicion of hypertension secondary to renal artery stenosis, caution should be exercised due to concern about worsening renal function. In summary, apart from certain expected adverse effects that are class effects from angiotensin-converting enzyme inhibitors and angiotensin receptor blockers, valsartan has demonstrated reasonable short-term safety in the pediatric population. Nonetheless, these data are based on limited experience with valsartan, and long-term safety data are rather limited.

\section{Conclusion}

Valsartan is a novel angiotensin receptor blocker that may have a plausible role in the pediatric population. With the increasing incidence of obesity and changes in lifestyle in developed and developing countries, the incidence of hypertension is bound to increase. Adolescent hypertension is suggested to be the precursor of adult hypertension, and trends in blood pressure during adolescence predict development of adult hypertension. ${ }^{31}$ Hypertension in children and especially adolescents is expected to increase to epidemic proportions. The need for newer, better tolerated antihypertensive treatment has led to the development of many new antihypertensive agents. Valsartan is one such agent, belonging to a class of angiotensin receptor blockers that is orally formulated and may be a reasonable choice for treating hypertension in children. The efficacy of valsartan has been demonstrated in the pediatric population aged 1-16 years. In addition to treatment of hypertension, valsartan may have a role to play in pediatric heart failure and kidney disease. Based on data in adults, it may be considered as one of the preferred agents in hypertensive children with diabetes or proteinuria. Its efficacy is comparable with that of other angiotensin receptor blockers approved for use in the pediatric population. Once-daily dosing tends to provide a sustained blood pressure-lowering effect over 24 hours. The recommended starting dose is $40 \mathrm{mg}$, which may be incrementally increased up to $160 \mathrm{mg}$ daily. Common side effects include headache and dizziness, and the latter may be dose-dependent. Limited data suggest that serious adverse effects requiring discontinuation of the drug are infrequent. Palatability is intermediate compared with other angiotensin receptor blockers. It does not appear to affect growth or development in children. Sexually active adolescent females should be counseled regarding effective contraceptive measures while taking valsartan. In summary, valsartan offers another option in the ever-increasing array of antihypertensive therapies in children, and may have a role in treating pediatric hypertension and many other pediatric diseases.

\section{Disclosure}

The authors report no conflicts of interest in this work.

\section{References}

1. Flynn JT. Successes and shortcomings of the FDA Modernization Act. Am J Hypertens. 2003;16:889-891.

2. Novartis Pharmaceuticals Corporation. Diovan ${ }^{\circledR}$ prescribing information. East Hanover, NJ: Novartis Pharmaceuticals Corporation; November 2007.

3. National High Blood Pressure Education Program Working Group on Hypertension Control in Children and Adolescents. Update on the 1987 task force report on high blood pressure in children and adolescents: A working group report from the National High Blood Pressure Education Program. Pediatrics. 1996;98:649-658.

4. National High Blood Pressure Education Program Working Group on High Blood Pressure in Children and Adolescents. The fourth report on the diagnosis, evaluation, and treatment of high blood pressure in children and adolescents. Pediatrics. 2004;114 Suppl 2:1-22. 
5. Munter P, He J, Cutler JA, Wildman RP, Whelton PK. Trends in blood pressure among children and adolescents. JAMA. 2004; 291:2107-2113.

6. Hajjar I, Kotchen T. Trends in prevalence, awareness, treatment, and control of hypertension in the United States, 1988-2000. JAMA. 2003;290:199-206.

7. Hansen ML, Gunn PW, Kaelber DC. Underdiagnosis of hypertension in children and adolescents. JAMA. 2007;298:874-879.

8. Beckett LA, Rosner B, Roche AF, et al. Serial changes in blood pressure from adolescence into adulthood. Am J Epidemiol. 1992;135: 1166-1177.

9. Robinson RF, Nahata MC, Batisky DL, et al. Pharmacologic treatment of chronic pediatric hypertension. Paediatr Drugs. 2005;7:27-40.

10. Kavey RE, Daniels SR, Flynn JT. Management of high blood pressure in children and adolescents. Cardiol Clin. 2010;28:597-607.

11. Balkrishnan R, Phatak H, Gleim G, Karve S. Assessment of the use of angiotensin receptor blockers in major European markets among paediatric population for treating essential hypertension. J Hum Hypertens. 2009;23:420-425.

12. Kotsis V, Stabouli S, Papakatsika S, Rizos Z, Parati G. Mechanisms of obesity-induced hypertension. Hypertens Res. 2010;33:38-93.

13. Wühl E, Trivelli A, Picca S, et al. Strict blood-pressure control and progression of renal failure in children. $N$ Engl $J$ Med. 2009;361: 1639-1650.

14. van Hooft IM, Grobbee DE, Derkx FH, de Leeuw PW, Schalekamp MA, Hofman A. Renal hemodynamics and the renin-angiotensin-aldosterone system in normotensive subjects with hypertensive and normotensive parents. N Engl J Med. 1991;324:1305-1311.

15. Egan BM, Basile JN, Rehman SU, et al. Plasma renin test-guided drug treatment algorithm for correcting patients with treated but uncontrolled hypertension: A randomized controlled trial. Am J Hypertens. 2009;22:792-801

16. Diovan ${ }^{\circledR}$ (valsartan) tablets. Prescribing information. East Hanover, NJ: Novartis Pharmaceuticals Corporation, 2008. Available from: http:// www.pharma.us.novartis.com/products/name/diovan.jsp. Accessed February 16, 2011.

17. Black HR, Bailey J, Zappe D, Samuel R. Valsartan: More than a decade of experience. Drugs. 2009;69:2393-2414.

18. Flesch G, Muller P, Lloyd P. Absolute bioavailability and pharmacokinetics of valsartan, an angiotensin II receptor antagonist, in man. Eur J Clin Pharmacol. 1997;52:115-120.

19. Blumer J, Batisky DL, Wells T, Shi V, Solar-Yohay S, Sunkara G. Pharmacokinetics of valsartan in pediatric and adolescent subjects with hypertension. J Clin Pharmacol. 2009;49:235-241.
20. Waldmeier F, Mueller PH, Flesch G, et al. Pharmacokinetics, disposition and biotransformation of valsartan (CGP 48933) in healthy male volunteers after a single oral dose of $80 \mathrm{mg}$ 14C-radiolabelled preparation. Xenobiotica. 1997;27:59-71.

21. Habtemariam B, Sallas W, Sunkara G, Kern S, Jarugula V, Pillai G. Population pharmacokinetics of valsartan in pediatrics. Drug Metab Pharmacokinet. 2009;24:145-152.

22. Flynn JT, Meyers KE, Neto JP, et al; Pediatric Valsartan Study Group. Efficacy and safety of the angiotensin receptor blocker valsartan in children with hypertension aged 1 to 5 years. Hypertension. 2008; $52: 222-228$

23. Wells T, Blumer J, Meyers KE, et al; The Valsartan Pediatric Hypertension Study Group. Years with hypertension. Effectiveness and safety of valsartan in children aged 6 to 16. J Clin Hypertens (Greenwich). 2011;13:357-365.

24. Jamerson KA, Zappe DH, Collins L, et al. The time to blood pressure (BP) control by initiating antihypertensive therapy with a higher dose of valsartan $(160 \mathrm{mg})$ or valsartan/hydrochlorothiazide compared to low-dose valsartan $(80 \mathrm{mg})$ in the treatment of hypertension: The VELOCITY study. J Clin Hypertens. 2007;9(5 Suppl A):A166.

25. Pool JL, Glazer R, Chiang YT, Gatlin M. Dose-response efficacy of valsartan, a new angiotensin II receptor blocker. J Hum Hypertens. 1999;13:275-281.

26. Shahinfar S, Cano F, Soffer BA, et al. A double-blind, dose-response study of losartan in hypertensive children. Am J Hypertens. 2005; 18(2 Pt 1):183-190.

27. Lubrano R, Soscia F, Elli M, et al. Renal and cardiovascular effects of angiotensin-converting enzyme inhibitor plus angiotensin II receptor antagonist therapy in children with proteinuria. Pediatrics. 2006;118:e833-e838.

28. Meier CM, Simonetti GD, Ghiglia S, et al. Palatability of angiotensin II antagonists among nephropathic children. Br J Clin Pharmacol. 2007; 63:628-631.

29. Destro M, Scabrosetti R, Vanasia A, et al. Comparative efficacy of valsartan and olmesartan in mild-to-moderate hypertension: Results of 24-hour ambulatory blood pressure monitoring. Adv Ther. 2005;22:32-43.

30. Hermida RC, Calvo C, Ayala DE, et al. Administration time-dependent effects of valsartan on ambulatory blood pressure in hypertensive subjects. Hypertension. 2003;42:283-290.

31. Tirosh A, Afek A, Rudich A, et al. Progression of normotensive adolescents to hypertensive adults: A study of 26,980 teenagers. Hypertension. 2010;56:203-209.

\section{Publish your work in this journal}

Adolescent Health, Medicine and Therapeutics is an international, peer-reviewed, open access journal focusing on health, pathology, and treatment issues specific to the adolescent age group. All aspects of health maintenance, preventative measures and disease treatmen interventions are addressed within the journal and practitioners from

\section{Dovepress}

all disciplines are invited to submit their work as well as healthcare researchers and patient support groups.. The manuscript management system is completely online and includes a very quick and fair peerreview system. Visit http://www.dovepress.com/testimonials.php to read real quotes from published authors. 